\title{
AVALIAÇÃO PRÉ-OCUPAÇÃO EM PONTO DE VENDA: ANÁLISE ERGONÔMICA E AMBIENTAL EM FRANQUIA ALIMENTÍCIA
}

\author{
SECCHI, Carla Cristina (1); \\ BINI, Carolina (2); \\ FERRARI, Marcela (3); \\ BINS ELY, Vera Helena Moro (4);
}

(1) UFSC, Mestranda no PósARQ UFSC

e-mail:arqcarlasecchi@gmail.com

(2) UFSC, Mestranda no PósARQ UFSC

e-mail:arqcarolinabini@gmail.com

(3) UFSC, Mestranda no PósARQ UFSC

e-mail:marcelaferrari.arg@gmail.com

(4) UFSC, Dr Eng, PósARQ UFSC

e-mail:vera.binsely@gmail.com

\begin{abstract}
RESUMO
O presente estudo consiste em uma avaliação pré-ocupação de um projeto de interiores, com enfoque na análise da Ergonomia e da Psicologia Ambiental. A pesquisa possui caráter exploratório e qualitativo, com abordagem multimetodológica, que consiste em levantamento físico, avaliação antropométrica, visita de exploração, predição comportamental e entrevistas. Com a pesquisa, buscou-se demonstrar a importância da realização de estudos e avaliações ainda na fase projetual, premeditando constrangimentos ergonômicos e ambientais, propondo soluções que visam a melhor qualidade no ambiente antes de sua execução. Concluiu-se que muitos dos problemas encontrados em franquias são passíveis de serem replicados pois seguem um projeto padrão.
\end{abstract}

Palavras chaves: Avaliação pré-ocupação; Ergonomia; Psicologia ambiental.

\begin{abstract}
The present study consists of a pre-occupation evaluation of an interior design, focusing on the analysis of Ergonomics and Environmental Psychology. The research has an exploratory and qualitative feature, with a multi-methodological approach, consisting in physical survey, anthropometric evaluation, exploration visits, behavioral prediction and interviews. With the research, it was tried to demonstrate the importance of studies and evaluations in the design phase, premeditating ergonomic and environmental constraints, proposing solutions that seek the best quality in the environment before execution. It was concluded that many of the problems found in franchises are likely to be replicated by following a standard design.
\end{abstract}

Keywords: Pre-occupation evaluation; Ergonomics; Environmental Psychology. 


\section{INTRODUÇÃO}

O presente trabalho possui como objetivo a avaliação pré-ocupação de uma franquia de produtos alimentícios ainda em fase projetual, buscando analisar possíveis problemas ergonômicos e prever o comportamento dos indivíduos no ambiente, evitando constrangimentos futuros que podem ser resolvidos antes de sua execução. Aborda a Ergonomia do Ambiente Construído e a Psicologia Ambiental, através de análises de disposição de layout, postos de trabalho e relações entre espaço do cliente e do funcionário utilizando esquemas gráficos, simulações digitais de manequins, visita de exploração/observação, levantamento físico e predição comportamental.

Resumidamente, a Ergonomia é a investigação da tarefa realizada pelo indivíduo no ambiente de trabalho e a adaptação dos meios para a sua realização de acordo com as características humanas. Já a Psicologia Ambiental estuda a relação entre o ambiente construído e o comportamento dos indivíduos (SILVEIRA; BINS ELY, 2015). Tais disciplinas auxiliaram os pesquisadores deste trabalho a percorrer o caminho correto para identificar constrangimentos no projeto e recomendar melhorias.

As análises de pré-ocupação da presente pesquisa foram elaboradas a partir do projeto realizado pelo escritório de arquitetura responsável pelas lojas da franquia. $O$ proprietário desta loja participou de todo o processo, auxiliando na avaliação realizada. Tal projeto está previsto para implantação em um espaço gourmet na cidade de Florianópolis - SC. Constitui- se em uma área pequena, de $22,50 \mathrm{~m}^{2} \mathrm{com}$ uma quantidade expressiva de tarefas e funções a serem exercidas pelos funcionários.

No ramo de comércios alimentícios, a grande variedade e quantidade de estabelecimentos existentes se destaca no nosso meio. Porém, pouco se ouve falar sobre a qualidade de trabalho dos funcionários nesses estabelecimentos, principalmente relacionando ergonomia e psicologia ambiental (SILVEIRA; BINS ELY, 2015). Uma das preocupações desta pesquisa foi a qualidade de trabalho dos funcionários, que poderiam apresentar dificuldades de exercer suas funções no pequeno espaço ofertado. É fato que a qualidade dos produtos oferecidos e da própria produção recebe interferência dependendo do estado físico e ou emocional dos funcionários.

No geral, as lojas de franquias encontram um grande problema em relação aos mobiliários e equipamentos, que normalmente seguem padrões e precisam se "adaptar" aos locais. Para melhorar a disposição e local de trabalho dos funcionários, os pesquisadores desenvolveram, ao longo da pesquisa, uma nova proposta de layout, com a intenção de adequar os espaços aos indivíduos, que será apresentada no decorrer do trabalho.

\section{METODOLOGIA}

A pesquisa possui caráter exploratório, interdisciplinar e qualitativo, com abordagem multimetodológica com métodos de Ergonomia e Psicologia Ambiental. A pesquisa que ocorreu ao longo de aproximadamente três meses, passou por fases de diagnóstico e aplicação dos procedimentos metodológicos, sendo: levantamento físico; avaliação antropométrica; visita de exploração/observação; predição comportamental; e entrevistas.

Primeiramente, os pesquisadores solicitaram autorização para a análise do estabelecimento ao proprietário, que já estava descontente com questões projetuais da franquia, aprovando a análise pré-ocupação do projeto de sua loja. Os pesquisadores deste estudo foram ao local de implantação da loja para o levantamento físico, onde realizaram medições e reconhecimento do local. Como auxílio no desenvolvimento das próximas etapas, uma visita de exploração/observação foi realizada na praça de 


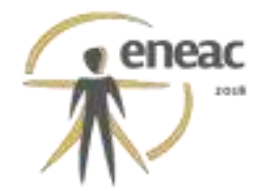

alimentação em um shopping center na cidade de Florianópolis - SC, onde foi possível analisar o comportamento de grupos de funcionários dentro de espaços com fluxos e funções semelhantes às adotadas pela franquia. Assim, aplicou-se a etapa de avaliação antropométrica, analisando os constrangimentos dos postos de trabalhos e atividades que seriam desenvolvidas por meio de simulação digital de plantas baixas e vistas, utilizando manequins. A predição do comportamento dos indivíduos no espaço foi a próxima etapa, por meio de fluxos em planta baixa, prevendo como ocorrerá a conduta dos funcionários no ambiente.

Com os problemas e constrangimentos encontrados no projeto analisado, através dos métodos de avaliação antropométrica e predição comportamental, os pesquisadores criaram uma nova opção de layout, reunindo-se com o proprietário para apresentar a proposta e discutir as melhores ideias. Após o desenvolvimento da proposta pelos pesquisadores, foram realizadas duas entrevistas, uma com o proprietário do estabelecimento, para verificar se a análise o ajudou a compreender melhor seu futuro estabelecimento e outra com uma chef de cozinha com comprovada experiência profissional, isenta de possíveis vícios e conceitos projetuais da franquia, que identificou a evolução das propostas e foi de fundamental importância para a pesquisa, pois essa atua em um comércio semelhante.

\section{RESULTADOS, DIAGNÓSTICO ERECOMENDAÇÕES}

Através dos métodos apresentados, os resultados foram abordados em duas fases: 1. Análise ergonômica, com levantamento físico, avaliação antropométrica e visita de exploração/observação; 2. Análise de Psicologia Ambiental, através da predição comportamental e entrevistas. Nessas duas fases são apresentados os problemas e constrangimentos encontrados, assim como as recomendações que resultaram no desenvolvimento da nova proposta de layout para o estabelecimento.

\subsection{Análise Ergonômica: Levantamento Físico}

No levantamento físico, constatou-se que algumas medidas do projeto não coincidiam com as medições in loco, ou seja, o espaço no projeto do escritório da franquia era aproximadamente $10 \mathrm{~cm}$ menor do que o local de implantação, além dos pontos de esgoto, água e gás não constarem no projeto, detalhes que interferem no layout.

\subsection{Análise Ergonômica: Avaliação Antropométrica}

Nesta etapa será apresentada a avaliação antropométrica realizada no projeto do escritório da franquia e na proposta definida pelos pesquisadores do estudo. $O$ programa de necessidades da loja (Tabela 01) conta com área para venda de produtos congelados e produtos prontos na hora, necessitando assim de uma estrutura completa de comércio alimentício.

\begin{tabular}{|c|c|}
\hline \multicolumn{2}{|c|}{ Tabela 01 - Programa de Necessidades e Quantidade de Funcionários } \\
\hline 1. Caixa de pedidos & 1 \\
\hline 2. Area de limpeza & 1 \\
\hline 3. Area de cocção & $1^{*}$ \\
\hline 4. Entrega dos pedidos & 1 \\
\hline $\begin{array}{l}\text { 5. Área de venda de massas congeladas e } \\
\text { demonstração de produtos }\end{array}$ & $1^{*}$ \\
\hline
\end{tabular}

* Segundo o proprietário do estabelecimento, pode-se adicionar mais um ajudante em cada um desses setores, dependendo do fluxo e demanda do espaço no decorrer do seu funcionamento.

Fonte: Os autores. 


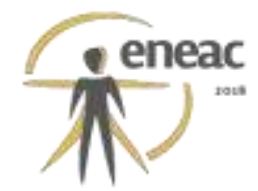

As medidas antropométricas utilizadas nesta pesquisa tiveram como aporte os estudos de PANERO e ZELNIK (2002). Para conferência das medidas em planta baixa e vistas, utilizou- se o percentil 95 de homens e o percentil 5 de mulheres, considerados os extremos da população, pois os funcionários do futuro estabelecimento ainda não foram contratados.

\subsubsection{Proposta 1: Elaborada pela Franquia}

A proposta - objeto de estudo dessa pesquisa (Figura 1), foi apresentada ao proprietário pelo escritório da franquia. Tal projeto foi analisado em relação à ergonomia dos espaços de trabalho e também quanto ao ambiente da loja. O projeto foi analisado e recomendações foram feitas.

Figura 1 - Planta Baixa - Projeto pela franquia

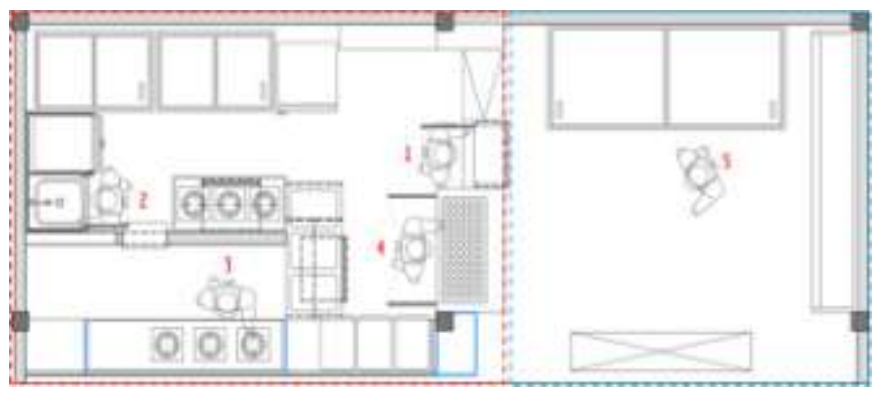

Legenda:

1. Funcionário do caixa;

2. Funcionário da limpeza; 3. Funcionário da área de cocção;

4.Auxiliar de entrega;

5. Auxiliar de vendas.

Fonte: Proprietário. Adaptado pelos autores.

As situações e constrangimentos encontrados foram nos seguintes postos de trabalho: 1. Funcionário do caixa; 2 . Funcionário da área de limpeza; e 3. Funcionário da área de cocção. Para entendimento das atividades de cada um desses funcionários, pesquisouse na CBO (Classificação Brasileira de Ocupações) suas funções. Também foram desenvolvidas análises de cada um desses funcionários, utilizando vistas com simulação de manequins para recomendar soluções às atividades.

\section{Funcionário do Caixa:}

Segundo o proprietário, o caixa terá a função de receber os pedidos dos clientes, informar à cocção e receber o pagamento pelos produtos congelados. A Tabela 2 identifica as atividades prescritas deste indivíduo, além dos conflitos encontrados no layout da Figura 1 e as recomendações realizadas pelos pesquisadores.

\begin{tabular}{|c|c|c|}
\hline & Tabela 2 - Funcionário do Caixa & \\
\hline arefa Pre & & \\
\hline $\begin{array}{l}\text { 4211-25 - OPERADOR DE CAIXA: } \\
\text { receber valores de vendas de } \\
\text { produtos e serviços; controlar } \\
\text { numerários e valores; tratar objetos; } \\
\text { prestar informações; realizar } \\
\text { atividades técnico-administrativas; } \\
\text { comunicar-se. }\end{array}$ & $\begin{array}{l}\text { 1. A área do caixa encontra-se em } \\
\text { conflito com o freezer. Assim, quem } \\
\text { está na fila para pagamento, bloqueia a } \\
\text { passagem de pessoas para escolha de } \\
\text { produtos no freezer. } \\
\text { 2. O funcionário tem que trabalhar de } \\
\text { pé todo o tempo. }\end{array}$ & $\begin{array}{l}\text { 1. Reposicionar o } \\
\text { freezer, que está em } \\
\text { conflito com a fila do } \\
\text { caixa; } \\
\text { 2. Planejar uma } \\
\text { banqueta para o } \\
\text { funcionário; }\end{array}$ \\
\hline
\end{tabular}

Fonte: Os autores. 


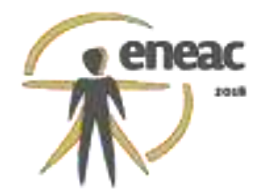

Foram desenvolvidas vistas com os percentis 95 para homem e 5 para mulher neste posto de trabalho, demonstrando tais conflitos e comparando as medidas do projeto e as recomendadas (Figura 2).

\section{Figura 2 - Vista das atividades do funcionário do caixa nos percentis 5 para mulheres $(1,50 \mathrm{~m})$ e 95 para homens $(1,85 \mathrm{~m})$}

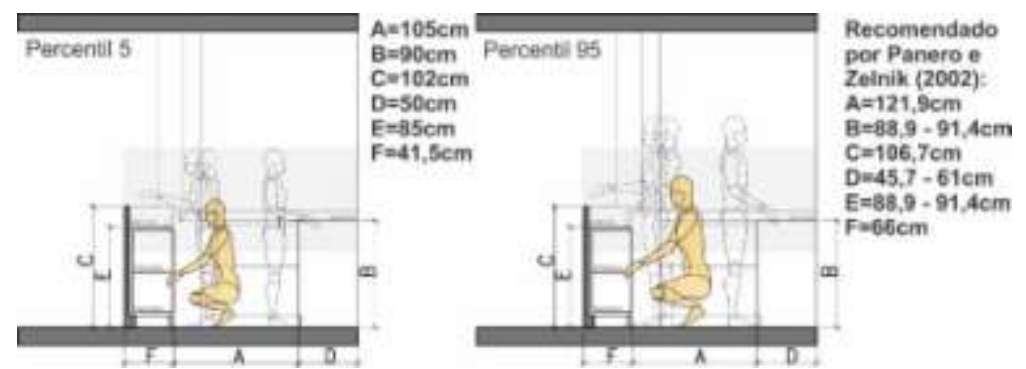

Fonte: Os autores.

Em relação às dimensões desta primeira proposta, percebe-se que há adequação da altura da bancada e das dimensões do mobiliário. Porém, o funcionário nesta situação deve trabalhar somente em pé. Em uma nova proposta, seria interessante a disposição de maior espaço para incluir uma banqueta no local de trabalho. A área de circulação está menor que o recomendado, assim como as dimensões de profundidade e altura do caixa, que dificultarão as atividades de pagamentos e atendimentos. Na vista de percentil 5, percebe-se que 0 indivíduo deve forçar a postura de alcance horizontal para receber e devolver o pagamento. No percentil 95, a maior dificuldade é abaixar-se para alcançar algo no móvel do caixa.

\section{Funcionário da Área de Limpeza:}

Segundo o proprietário, o funcionário da área de limpeza possui como função manter a loja limpa e organizada. Na Tabela 3 estão descritas as atividades pela CBO, além dos conflitos encontrados e as recomendações dos pesquisadores.

\begin{tabular}{|c|c|c|}
\hline \multicolumn{3}{|c|}{ Tabela 3 - Funcionário da Área de Limpeza } \\
\hline Tarefa Prescrita (CBO) & Conflitos Encontrados & Recomendações \\
\hline $\begin{array}{l}\text { 5135-05 - AUXILIAR NOS SERVIÇOS } \\
\text { DE ALIMENTAÇAO: } \\
\text { Pré-preparar alimentos; auxiliar na } \\
\text { montagem de pratos; processar } \\
\text { alimentos; montar praça ("mise-en- } \\
\text { place"); verificar qualidade dos gêneros } \\
\text { alimentícios; minimizar riscos de } \\
\text { contaminação; preparar local de } \\
\text { trabalho; organizar trabalho; } \\
\text { demonstrar competências pessoais. }\end{array}$ & $\begin{array}{l}\text { 1. Não há apoio no local de } \\
\text { recebimento de utensílios } \\
\text { sujos; } \\
\text { 2. A área da pia de lavação é } \\
\text { muito restrita, não há } \\
\text { circulação adequada. } \\
\text { 3. Não há apoio para } \\
\text { secagem dos utensílios; } \\
\text { 4. Não há apoio para } \\
\text { devolucão dos utensílios. }\end{array}$ & $\begin{array}{l}\text { 1. Criar local de apoio para } \\
\text { a recepção de utensílios; } \\
\text { 2. Ampliar o local de } \\
\text { lavação; } \\
\text { 3. Criar local para apoiar os } \\
\text { utensílios na secagem; } \\
\text { 4. Criar apoio para } \\
\text { devolução dos utensílios à } \\
\text { cocção. }\end{array}$ \\
\hline
\end{tabular}

Fonte: Os autores.

Em relação às vistas desenvolvidas da área de limpeza (Figura 3), percebe-se que o percentil 5 tem mais dificuldade para realizar atividades na área de lavação, como o alcance da torneira. 0 percentil 95 possui dificuldade em se agachar devido à pequena área livre para evolução/circulação. 


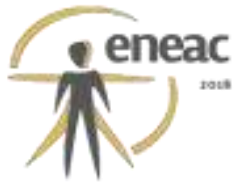

Figura 3 - Vista das atividades do funcionário da limpeza nos percentis 5 para mulheres $(1,50 \mathrm{~m})$ e 95 para homens $(1,85 \mathrm{~m})$

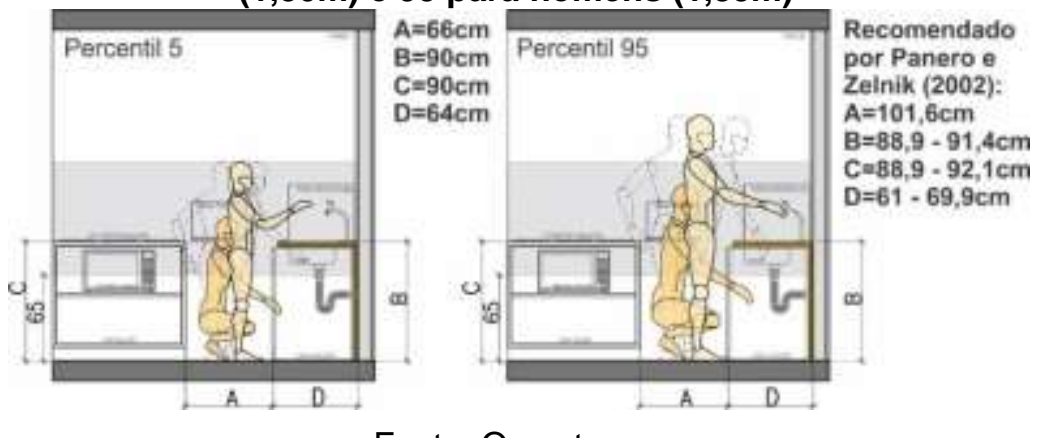

Fonte: Os autores.

\section{Funcionário da Área de Cocção:}

De acordo com o proprietário, o funcionário da área de cocção será o responsável por cozinhar os produtos, preparar os pratos e finalizar a montagem, enviando para a entrega. A Tabela 4 identifica as atividades prescritas pela $\mathrm{CBO}$, assim como os conflitos encontrados neste posto de trabalho e as recomendações dos pesquisadores.

\begin{tabular}{|c|c|c|}
\hline \multicolumn{3}{|c|}{ Tabela 4 - Funcionário da Área de Cocção } \\
\hline Tarefa Prescrita (CBO) & Conflitos Encontrados & Recomendações \\
\hline $\begin{array}{l}5132-05 \text { - } \\
\text { COZINHEIRO GERAL: } \\
\text { Preparar alimentos; } \\
\text { finalizar alimentos; pré- } \\
\text { preparar alimentos; } \\
\text { planejar rotina de } \\
\text { trabalho; iniciar } \\
\text { atividades na cozinha; } \\
\text { fechar cozinha; } \\
\text { proceder estocagem e } \\
\text { conservação de } \\
\text { alimentos; comunicar- } \\
\text { se; demonstrar } \\
\text { competências } \\
\text { pessoais. }\end{array}$ & $\begin{array}{l}\text { 1. A ajuda necessária do funcionário da limpeza } \\
\text { no alcance de produtos do freezer e geladeira } \\
\text { para o funcionário da cocção prejudica sua } \\
\text { tarefa, pois precisa deixar o que está fazendo e } \\
\text { entregar tal produto. Deve-se encontrar outra } \\
\text { alternativa de acesso; } \\
\text { 2. O micro-ondas está muito afastado da área } \\
\text { de cocção; } \\
\text { 3. Importante verificar a altura da bancada em } \\
\text { relação à altura da panela; } \\
\text { 4. Não há apoio entre os cooktops, além de } \\
\text { existirem em áreas separadas, necessitando de } \\
\text { mais um funcionário para operar; } \\
\text { 5. O vidro que divide a área de cocção com área } \\
\text { de entrega dificulta a manobra de entrega; } \\
\text { 6. Não há um local para lavação. }\end{array}$ & $\begin{array}{l}\text { 1. Encontrar outra } \\
\text { alternativa de acesso para } \\
\text { área de cocção-limpeza; } \\
\text { 2. Trazer o micro-ondas } \\
\text { para a área de cocção; } \\
\text { 3. Definir altura da panela } \\
\text { para projetar a altura da } \\
\text { bancada; } \\
\text { 4. Criar área de apoio } \\
\text { entre cooktops e } \\
\text { posicioná-los na mesma } \\
\text { bancada; } \\
\text { 5. Resolver posição do } \\
\text { vidro que divide as áreas } \\
\text { de cocção e entrega; } \\
\text { 6. Prever local para } \\
\text { lavação. }\end{array}$ \\
\hline
\end{tabular}

Fonte: Os autores.

A área de cocção é o posto de trabalho que mais apresentou problemas. Das cinco dimensões analisadas, apenas a altura da bancada está de acordo com Panero e Zelnik (2002).

Figura 4 - Vista das atividades do funcionário da área de cocção nos percentis 5 para mulheres $(1,50 \mathrm{~m})$ e 95 para homens $(1,85 \mathrm{~m})$

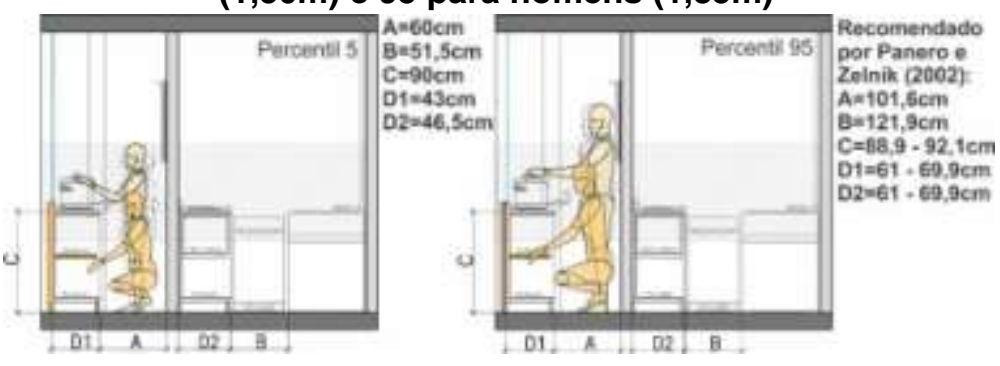

Fonte: Os autores. 


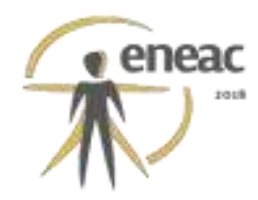

Na Figura 4, os dois percentis têm dificuldades semelhantes na atividade prescrita. O espaço entre a parede e a bancada é menor do que o mínimo adequado, tornando difíceis as atividades de agachamento e de rotação para alcançar os produtos. Além disso, a altura da bancada e da panela são inadequadas para o percentil 5 , que faz movimentos prejudiciais no momento de abrir a panela.

Os problemas ergonômicos encontrados, podem ser classificados, segundo Moraes e Mont'Alvão (2003) através da Taxionomia dos problemas ergonômicos do sistema: Homem x Tarefa x Máquina, em:

Interfaciais: Posturas prejudiciais resultantes de inadequações do campo de visão, tomada de informações, alcances etc, que causam prejuízos para os sistemas muscular esquelético. Instrumentais: Arranjos físicos impróprios de painéis de informações e de comandos, que acarretam dificuldades de tomada de informações e de acionamentos, que causam prejuízo para memorização e aprendizagem. Espaciais/Arquitetura de Interiores: Deficiência de fluxo, circulação e isolamento, que causam problemas ergonômicos e de locomoção.

Nesta proposta, também se percebeu que não há espaço social para os funcionários, dificultado pelo espaço pequeno.

\subsubsection{Proposta 2: Elaborada pelos Pesquisadores}

Na proposta desenvolvida pelos pesquisadores (Figura 5), foram feitas alterações de acordo com as análises apresentadas anteriormente, realizadas no projeto da franquia, seguindo as recomendações para cada posto de trabalho das tabelas 2,3 e 4.

Figura 5 - Planta Baixa - Terceira Proposta

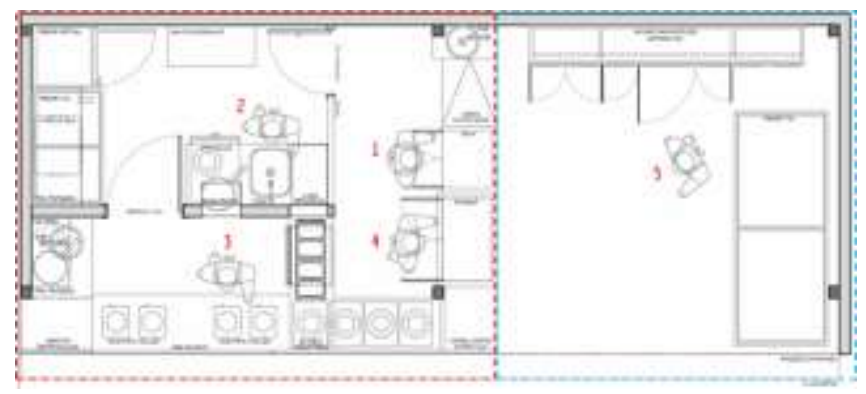

Legenda:

1. Funcionário do caixa;

2. Funcionário da limpeza;

3. Funcionário da área de cocção;

4.Auxiliar de entrega;

5. Auxiliar de vendas.

Fonte: Autores.

Nesta proposta, também serão apresentadas separadamente as análises dos postos de trabalho do caixa, limpeza e cocção, utilizando vistas e simulação com manequins, apontado as melhorias realizadas a partir das recomendações.

\section{Funcionário do Caixa:}

Os pesquisadores procuraram adequar os ambientes ao conforto dos funcionários. $\mathrm{Na}$ proposta anterior, o funcionário do caixa deveria trabalhar em pé todo o tempo. No novo projeto, tal indivíduo pode sentar nas horas de menor movimento em uma banqueta disposta em seu posto de trabalho, possibilitado pela nova profundidade do mobiliário. $O$ freezer no acesso também foi reposicionado, melhorando o fluxo entre clientes que manuseiam o freezer e os clientes que fazem seus pedidos no caixa. 


\section{ranes}

Figura 6 - Vista das atividades do funcionário do caixa nos percentis 5 para mulheres $(1,50 \mathrm{~m}) \mathrm{e}$ 95 para homens $(1,85 \mathrm{~m})$

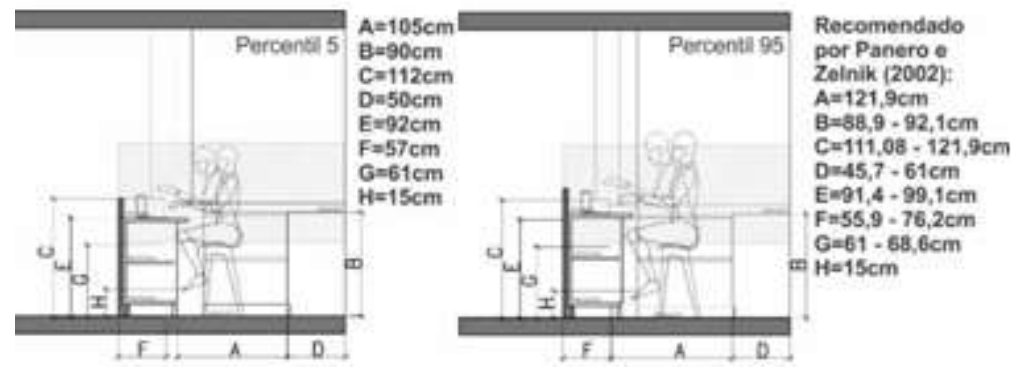

Fonte: Os autores.

De acordo com as vistas acima (Figura 6), a maioria das medidas foram readequadas e estão dentro do recomendado, mas ainda existem problemas de circulação (medida A), sendo essa a única medida que não foi possível alterar sem prejuízo de outras atividades, devido ao espaço pequeno da loja.

\section{Funcionário da Área de Limpeza:}

A área de limpeza foi relocada paralela à área de cocção, tornando possível que o funcionário da área de limpeza observe o que o funcionário da área de cocção realiza e prever qual sua necessidade (Figura 5). Nem todas as dimensões foram alteradas segundo Panero e Zelnik (2002), mas proporcionam maior conforto ao usuário.

As soluções propostas para essa área foram: 1. Á área de limpeza foi escondida por um painel, para que o cliente não visualize; 2 . O layout foi modificado, com o objetivo de melhorar o fluxo interno e a organização, diminuindo conflitos entre tarefas; 3 . Os freezers foram dispostos em local mais próximo à área de cocção e a área de lavação ficou mais próxima do passa pratos, que ganhou área de apoio; 4. Os utensílios foram pendurados na parede para secar; 5. As lixeiras (orgânica e reciclável) foram dispostas abaixo da área de lavação, em local refrigerado.

As vistas da Figura 7 mostram os funcionários no novo layout da área de limpeza. Em relação aos dois percentis, percebe-se que há maior espaço para as atividades, sendo mais fácil se agachar.

Figura 7 - Vista das atividades do funcionário da área de limpeza nos percentis 5 para mulheres $(1,50 \mathrm{~m})$ e 95 para homens $(1,85 \mathrm{~m})$
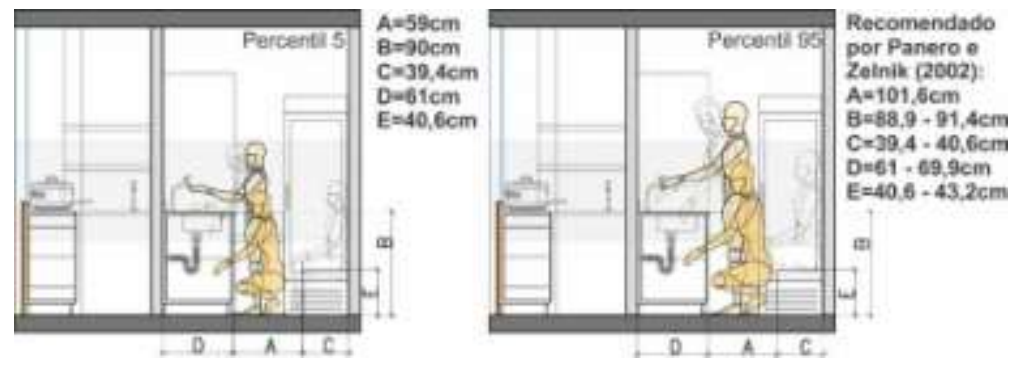

Fonte: Os autores.

Grande parte das medidas foi adequada conforme o recomendado (Figura 7), porém o problema continua na circulação (medida A), devido ao espaço pequeno da loja.

\section{Funcionário da Área de Cocção:}


torne o responsável pela função, pois seu espaço é menor do que o necessário para receber todas as atividades prescritas. Na primeira proposta existiam duas bancadas de cocção, e dois funcionários para realizar a mesma atividade, ocupando mais espaço do que o necessário. Os freezers também ficaram mais próximos, possibilitando a busca de produtos pelo funcionário, sem precisar do auxílio de outros que deixam de fazer suas tarefas. Um armário refrigerado foi pensado para existir abaixo da bancada de cocção, facilitando a atividade do cozinheiro. Uma cuba também foi posicionada na bancada lateral, garantindo a higienização rápida do funcionário.

O vidro que separava a área de entrega também foi reposicionado, permitindo a passagem livre de bandejas com pedidos prontos para entrega ao cliente. De acordo com informações do proprietário, as bandejas e pratos sujos serão limpos em uma lavanderia geral da praça de alimentação e depois devolvidos à loja. Prateleiras localizadas na área de cocção facilitam o alcance de pratos e panelas. Além dessas soluções, outras foram propostas, como a inserção de dois passa pratos (um louça limpa, um suja). A Figura 8, mostra a atividade dos dois percentis na área de cocção. Umma nova panela foi introduzida na área de cocção, mais larga e mais baixa do que a anterior, para diminuir o esforço do funcionário de percentil 5 , mas não prejudicando aquele com percentil 95.

\section{Figura 8 - Vista das atividades do funcionário da área de cocção nos percentis 5} para mulheres $(1,50 \mathrm{~m})$ e 95 para homens $(1,85 \mathrm{~m})$

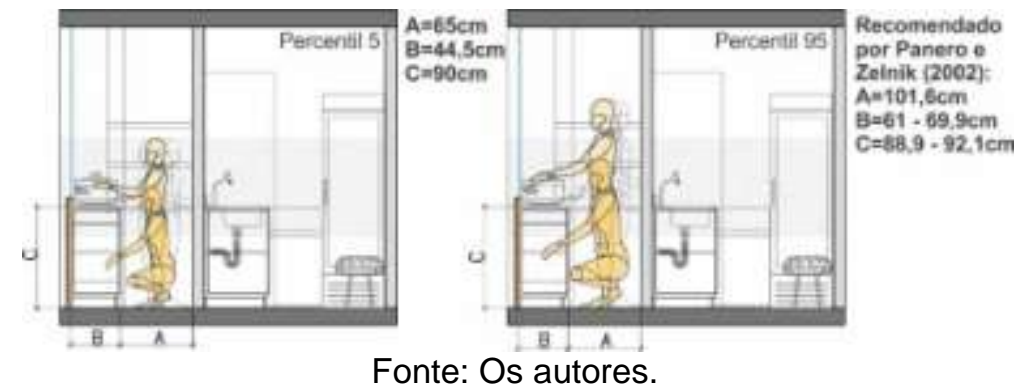

Na proposta realizada pelos pesquisadores, a área de cocção foi o local mais difícil de ser resolvido. A altura do fogão é adequada ao funcionário, mas a profundidade e zona mínima de trabalho continuam deficientes (Figura 8). Levando em consideração o descanso dos funcionários, neste layout foi proposto um banco na área interna da loja, localizado na área de limpeza, que também serve como baú para guardar os pertences dos funcionários. $O$ banco não dificulta o fluxo e movimento nas atividades prescritas.

As recomendações feitas nesta proposta foram enviadas ao proprietário da loja, que acatou as melhorias e decidiu que este layout seria executado em definitivo.

\subsection{Análise de Predição Comportamental}

$\mathrm{Na}$ análise comportamental, foram analisadas as duas propostas já apresentadas na fase ergonômica, porém agora relacionando seus fluxos e fazendo uma predição da prática dos funcionários no espaço, entendendo os constrangimentos, problemas e soluções que podem ser adotados em relação ao comportamento no local.

\subsubsection{Proposta 1: Elaborada pela Franquia}

Na proposta 1 realizada pela franquia, os fluxos de trabalho (Figura 9) são impedidos pela parede central (fluxo de pedidos com vendas de massas congeladas; comunicação pedido; passagem de pratos sujos e limpos pelo mesmo local; e passagem de pedidos para entrega). Os fluxos que prejudicam as atividades dos funcionários serão apresentados através da predição de fluxos de comportamento: 


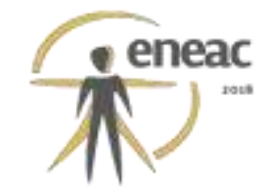

Figura 9 - Planta baixa primeira proposta, com fluxos de funcionários e clientes

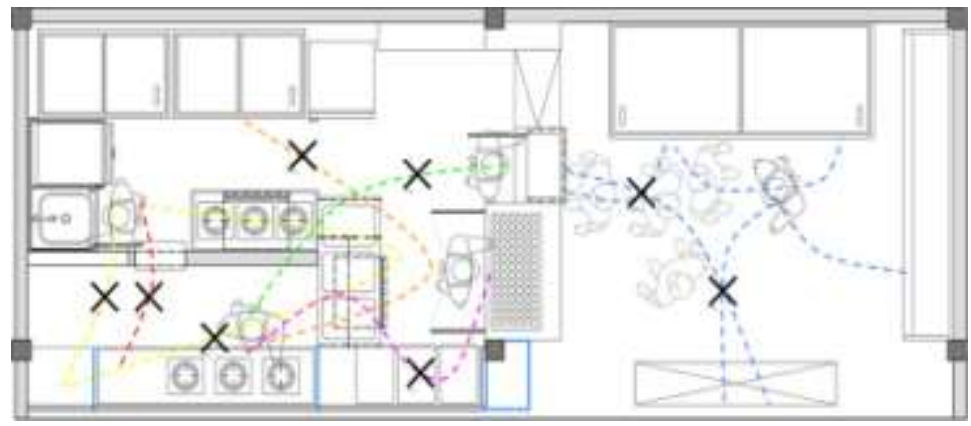

Fonte: Os autores.

Os conflitos encontrados na figura 9 foram demonstrados em forma de linhas pontilhadas de diferentes cores, identificadas na Tabela 5.

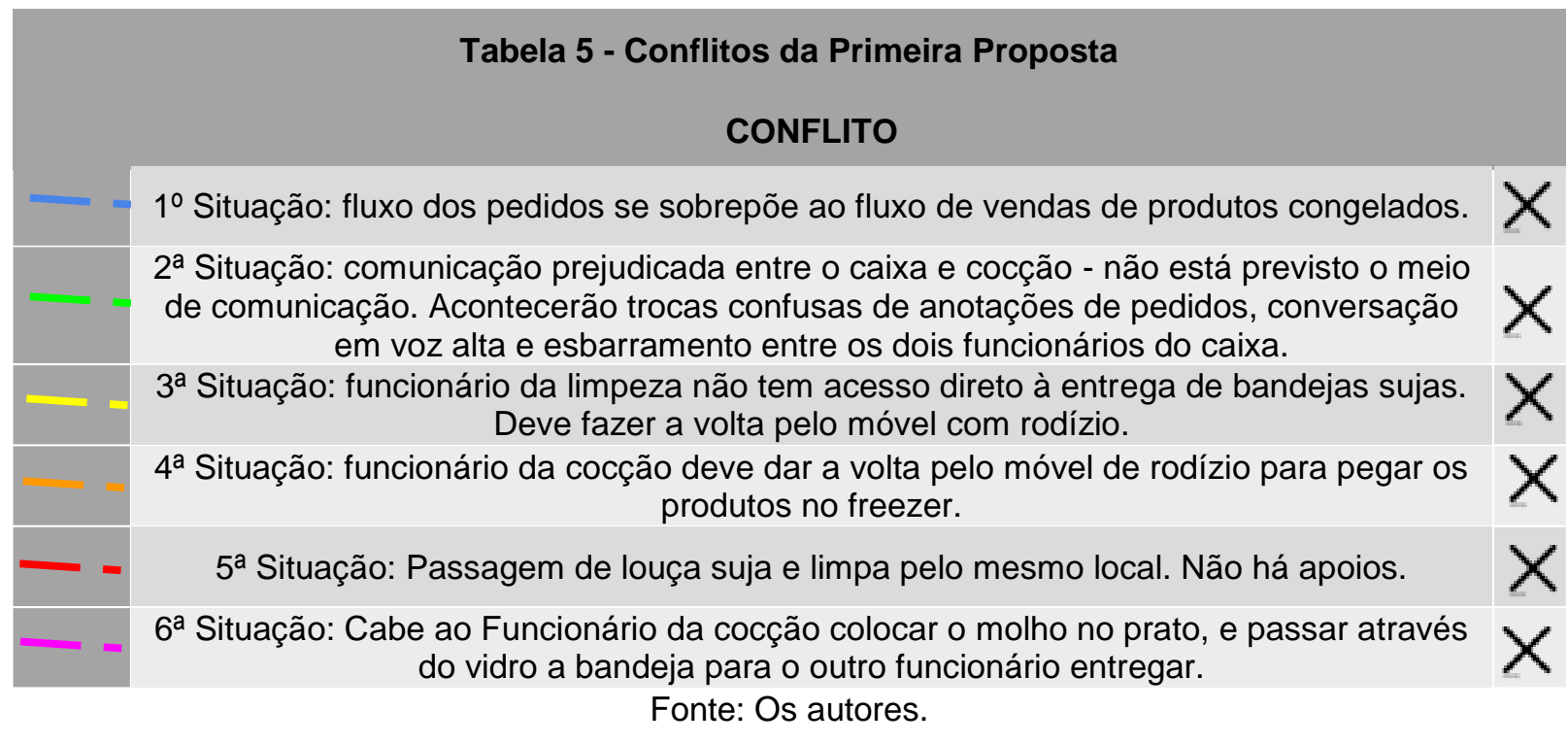

\subsubsection{Proposta 2: Elaborada pelos Pesquisadores}

$\mathrm{Na}$ proposta desenvolvida pelos pesquisadores (Figura 10), o layout foi pensado para melhorar os fluxos de trabalho, fazendo com que o comportamento dos funcionários no espaço não ocasione constrangimentos, colisões e falta de comunicação. Além disso, cada indivíduo deve conseguir ocupar o território designado para sua função. A melhoria no projeto também pode exercer aspectos positivos na interação visual entre os funcionários.

Figura 10 - Planta baixa terceira proposta, com fluxos de funcionários e clientes

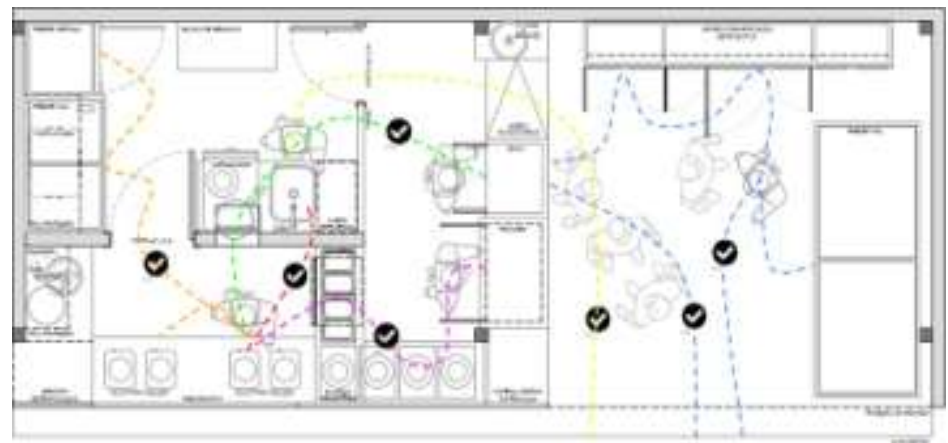

Fonte: Os autores. 


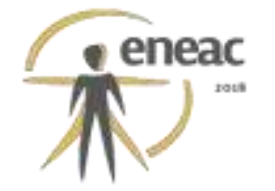

A segunda proposta teve como diretriz os fluxos de clientes e funcionários. Todo o layout foi pensado para adequar a passagem dos trabalhadores sem que conflitos ocorressem constantemente. A Tabela 6 identifica tais soluções.

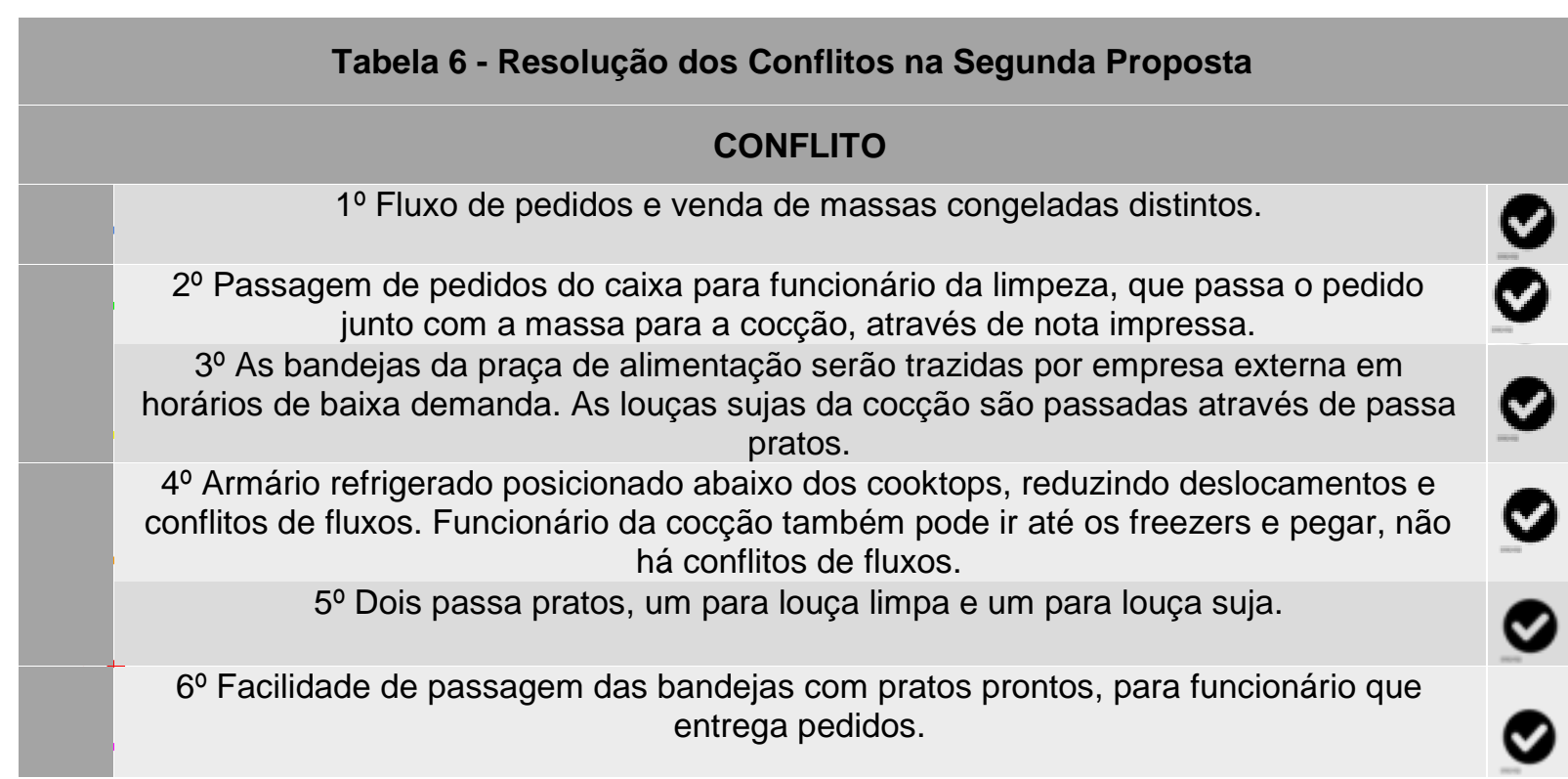

Fonte: Os autores.

\subsection{Análise da percepção: Entrevistas}

Ao final do trabalho foram realizadas duas entrevistas, uma com uma chef de cozinha que não possui relação com a franquia em estudo e outra com o proprietário do estabelecimento.

A entrevista com a chef auxiliou na compreensão da proposta elaborada pelos pesquisadores e avaliou se, de fato, as modificações foram positivas. Segundo a Chef, os principais problemas eram a falta de bancadas de apoio, o posicionamento dos equipamentos e o fluxo da cocção, que foram resolvidos na proposta pelos pesquisadores.

Através da entrevista realizada com o proprietário, identificaram-se as dificuldades encontradas no processo de contratação de projetos de franquia, assim como o avanço e melhor entendimento do projeto através das análises presentes neste estudo. O proprietário apontou que no projeto elaborado à distância, o escritório tem dificuldades para alinhar a linguagem da franquia com o estilo da nova loja, esquecendo muitas vezes de determinações técnicas e ergonômicas. Sobre a segunda proposta, o proprietário apontou que foi feito um alinhamento entre o fluxo de trabalho, exigências técnicas e visuais, reforçando ainda que a análise de pré-ocupação é fundamental para adequar o espaço físico com rotinas da loja e número de pessoas, o que não seria possível prever sem a análise realizada.

\section{CONSIDERAÇÕES FINAIS}

Por meio deste trabalho, mostrou-se a grande vantagem da realização de um estudo de préocupação, pois vários problemas encontrados puderam ser apontados e corrigidos, evitando retrabalhos futuros que prejudicam o dia-a-dia dos funcionários e clientes do espaço, assim como prejuízo financeiro para o proprietário do estabelecimento.

O proprietário da loja revelou um feedback positivo ao grupo de pesquisadores, já que se sente mais seguro para executar o projeto depois de todo o estudo realizado, passando a reconhecer e valorizar as necessidades ergonômicas e fluxos apontados nesta pesquisa, já 


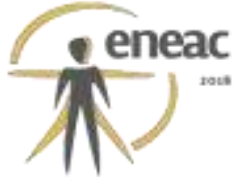

que o projeto da franquia não contemplava: "[...] adequar posicionamento, equipamentos e disposição das atividades de acordo com padrões ergonômicos mínimos e dentro de limites razoáveis, são fatores que contribuem para um ambiente de trabalho mais adequado e que podem minimizar a rotatividade e insatisfação da equipe [...]" (Proprietário).

Também se observou o pré-dimensionamento de praças de alimentação, que disponibilizam espaços com áreas mínimas para o funcionamento de diversos restaurantes. Tais espaços são insuficientes para abrigar o programa de necessidades que os restaurantes possuem. A segunda proposta, desenvolvida pelos pesquisadores neste trabalho passou por esse problema, pois algumas atividades tiveram que ocorrer em espaços menores, mas da melhor forma possível, procurando conforto e segurança aos funcionários.

O estudo também buscou apresentar as dificuldades de se trabalhar com projetos de franquia, que já tem dimensões estipuladas e devem ser adaptados ao lugar, descartando qualquer planejamento exclusivo e o contexto de inserção. O avanço nos meios de comunicação facilita a realização de projetos à distância, mas tais projetos ficam deficientes por não se adaptarem ao local de implantação. Assim, o layout de mobiliário e equipamentos se "encaixa" no espaço, tornando o projeto deficiente.

O cruzamento das informações obtidas pelas diferentes metodologias utilizadas permitiriu a elaboração de um conteúdo rico para a análise de pré-ocupação ergonômica e ambiental, concluindo que é possível analisar um projeto antes de sua execução e prever futuros problemas que podem ser solucionados.

Para estudos futuros, pretende-se realizar uma avaliação pós-ocupação da loja, analisando os resultados da execução do projeto de interiores e observando se as atividades prescritas avaliadas neste artigo possuem funcionamento adequado em horário comercial. Entrevistas com os funcionários podem verificar a operação correta destas atividades e novas medições podem ser feitas, personalizando os manequins com as dimensões de cada indivíduo.

\section{REFERÊNCIAS BIBLIOGRÁFICAS}

BRASIL, Ministério do Trabalho. Classificação Brasileira de Ocupações. Disponível em: <http://www.mtecbo.gov.br/cbosite/pages/home.jsf>. Acesso em: 30 nov. 2017.

MORAES, A. de; MONT'ALVÃO, C. Ergonomia, Conceitos e Aplicações. Rio de Janeiro: iUsEr, 2003. $3^{3}$ ed.

NOEBAUER, M. P. B.; BINS ELY, V. H. M.; CARRILHO, A. Atmosfera do Ponto de Venda: Recomendações Projetuais para Joalherias. In: Encontro Nacional de Tecnologia do Ambiente Construído, 2014, Maceió. Anais... Maceió, 2014.

PANERO, Julius; ZELNIK, Martin. Dimensionamento humano para espaços interiores: um livro de consulta e referência para projetos. Barcelona: GG, c2002. 320 p.

SILVEIRA, Carolina Morgado F.; BINS ELY, VERA HELENA MORO. Avaliação do trabalho dos atendentes em panificadora sob o viés da psicologia ambiental e da ergonomia. In: Encontro Nacional e Latino-Americano de Conforto no Ambiente Construído (XIII ENCAC/ IX ELACAC), 2015, Campinas. Anais do XIII ENCAC/ IX ELACAC, 2015. 